\title{
New multidimensional approaches to poverty measurement in Bosnia and Herzegovina
}

\author{
Adela Delalić \\ School of Economics and Business, University of Sarajevo, \\ Bosnia and Herzegovina \\ adela.delalic@efsa.unsa.ba \\ Rabija Somun - Kapetanović \\ School of Economics and Business, University of Sarajevo, \\ Bosnia and Herzegovina \\ rabija.somun@efsa.unsa.ba

\section{Emina Resić} \\ School of Economics and Business, University of Sarajevo, \\ Bosnia and Herzegovina \\ emina.resic@efsa.unsa.ba
}

\begin{abstract}
Unlike the standard unidimensional poverty indices, based mostly on monetary poverty measures, multidimensional poverty indices may include numerous nonmonetary poverty indicators. This study utilized fuzzy and Alkire - Foster (AF) and fuzzy methodology to assess the poverty level in Bosnia and Herzegovina (B\&H) and to compare the results with official poverty assessments. In addition to consumption as a monetary measure, we constructed AF and fuzzy indices by including numerous non-monetary measures that indicate housing quality, possession of durable goods and the household structure. AF multidimensional indices for B\&H are calculated based on data from Household Budget Surveys (2004, 2007 and 2011) and fuzzy poverty indices are calculated based on data from HBS 2011. This research has found the differences in the values, direction and dynamics between unidimensional and multidimensional approaches to poverty measurement. Authors state that it is not sufficient to base the creation of more efficient social policies and poverty reduction strategies exclusively on unidimensional indices that address just one dimension of poverty.
\end{abstract}

Keywords: Alkire - Foster poverty indices, fuzzy poverty indices, multidimensional poverty in B\&H

JEL classification: 1131, 1132

DOI: 10.1515/crebss-2017-0001

Received: March 25, 2017

Accepted: June 26, 2017 


\section{Introduction}

Official analysis and estimation of poverty in Bosnia and Herzegovina is based on the most comprehensive survey in this country - Household Budget Survey. Since now, four waves of the survey were conducted, in 2004, 2007, 2011 and 2015. The datasets from the last wave of HBS were not available at the moment of the research. In Bosnia and Herzegovina, such as in the most of other countries, evaluation of social policies and strategies for reduction of poverty is based on one monetary poverty indicator, income or consumption, and corresponding unidimensional poverty indices.

The numerous of studies and researches emphasize poverty as a multidimensional phenomenon. The goal of this study is to supplement and enrich official analysis of poverty in $\mathrm{B} \& \mathrm{H}$ with the measures that respect multidimensional nature of poverty. Aiming to construct multidimensional poverty indices, datasets from HBS 2004, 2007 and 2011 were analyzed in order to select appropriate monetary and nonmonetary poverty indicators. This study utilized two multidimensional poverty indices: adjusted headcount ratio based on Alkire - Foster method and fuzzy multidimensional poverty index.

Indices from the class of Alkire - Foster indices are primarily intended to multidimensional measurement of poverty. Considering that these indices satisfied the most of the axioms for multidimensional poverty measurement, they were highlighted in the recent studies of poverty. Their significance is emphasized by adopting Alkire - Foster method in construction of Multidimensional Poverty Index (MPI). Since 2010, MPI is integral part of UN Human Development Reports.

Fuzzy set theory is applicable in poverty analysis thanks to the fact that it doesn't treat population units explicitly as poor or nonpoor. Instead of that, there is defined the poverty membership function which represents the level of being affected by poverty. The advantage of fuzzy poverty indices, in comparison to other poverty indices, is absence of requirement for predefined poverty thresholds. Thanks to the poverty membership function, each population unit is more or less poor considering chosen poverty indicators. The level of poverty across indicators can be aggregate into overall level of poverty and thus constructed composite multidimensional poverty index.

Aiming to examine the differences between results obtained by unidimensional and multidimensional poverty measurement, unidimensional Foster - Greer Thorbecke indices and two chosen multidimensional indices were compared. This study confirmed that there are significant differences in structure and dynamics of poverty in Bosnia and Herzegovina, measured by unidimensional and multidimensional approach. Accordingly, future policies and strategies for reducing of poverty, and especially evaluation of their efficiency, should be based both on results unidimensional and multidimensional poverty analysis.

\section{Literature review}

In addition to multidimensional poverty indices obtained by generalization of standard unidimensional poverty indices, many authors emphasize the importance and advantages of Alkire - Foster (AF) and fuzzy multidimensional indices: Ambrosio, Deutsch and Silber (2011), Betti et al., (2006), Alkire and Foster $(2007,2011)$ and Alkire and Santos $(2011,2013)$.

Alkire and Foster $(2007,2011)$ proposed new methodology - family of multidimensional poverty indices $M_{a}$, for direct poverty measurement. The new methodology includes two types of poverty thresholds: first within each indicator and 
second across the indicators. The aggregation process is based on Foster - Greer Thorbecke poverty measures. Authors emphasize desirable characteristics of new multidimensional indices - satisfaction of numerous axioms for multidimensional poverty measurement and also possibility of using ordinal poverty indicators.

Alkire and Santos $(2011,2013)$ constructed Multidimensional Poverty Index, based on Alkire - Foster methodology, for 104 developing countries. MPI includes three dimensions of poverty: health, education and standard of living. In this study, for the first time, multidimensional poverty is estimated based on micro datasets (household surveys). In their second paper (2013) authors analyzed the scope and robustness of $\mathrm{MPI}$. Conclusion of this study is that MPI represents reliable measure that can be complemented with traditional income based poverty estimates.

Based on works of Cerioli and Zani (1990) and Cheli and Lemmi (1995), Betti et al. (2006) made further methodological conceptualization of totally fuzzy and relative approach to multidimensional poverty measurement. They examined choice of membership functions, choice of rules for the manipulation with resulting fuzzy sets and also the relationship between proposed fuzzy monetary measure and Gini coefficient.

Deutcsch and Silber (2006), based on data on Israeli Census 1995, examined differences and similiarities between identification of poverty based on three different approaches to fuzzy poverty measurement: totally fuzzy and relative, totally fuzzy and Vero \& Werquin approach. They identified the significance of poverty determinants by using logit regression and Shapley decomposition of marginal effects. Ambrosio et al. (2011) conducted similar research based on data in Belgium, France, Germany, Italy and Spain. Authors used two fuzzy approaches (totally fuzzy and totally fuzzy and relative) such as axiomatic approach (generalization of Foster Greer - Thorbecke indices) of poverty measurement.

\section{Theoretical background}

The aim of this study is to present theoretical background of construction chosen multidimensional poverty indices, based on Alkire - Foster and fuzzy sets methodology, such as to apply these methods on data in Bosnia and Herzegovina.

\section{Alkire - Foster multidimensional indices}

Alkire and Foster (2007) developed new class of multidimensional poverty indices based on Foster-Greer-Thorbecke poverty indices that capture joint distribution of deprivation and satisfy a large number of axioms for poverty measurement. UN adopted this method 2010 for calculation of Multidimensional Poverty Index (MPI) based on indicators of health, education and standard of living.

Generally, AF method includes different poverty/deprivation indicators and is based on overlapping or multiple deprivations by indicators. The observational unit is considered as multidimensionally poor if the weighted sum of its deprivations is higher than defined poverty threshold. The most common and the simplest AF index is adjusted headcount ratio:

$$
M_{0}=P_{0} \cdot A_{s},
$$

which is the product of multidimensional headcount ratio $P_{0}$ (the proportion of units identified as poor) and the average deprivation share - average poverty intensity As.

Adjusted headcount ratio shows incidence and intensity of poverty at the same time. The advantage of this index is ability to utilize cardinal and ordinal data. 
The next index from AF class is the adjusted poverty gap index:

$$
M_{1}=M_{0} \cdot P_{1}=P_{0} \cdot A_{s} \cdot P_{1} \text {. }
$$

It is calculated by multiplying adjusted headcount ratio Mo with the average poverty depth across all dimensions - multidimensional poverty gap index $P_{1}$. $M_{1}$ indicates incidence, intensity and depth of poverty and can be calculated based on cardinal, but not ordinal data.

The adjusted squared poverty gap index, or adjusted poverty severity index is product of adjusted headcount ratio and multidimensional poverty severity index $P_{2}$ :

$$
M_{2}=M_{0} \cdot P_{2}=P_{0} \cdot A_{s} \cdot P_{2} \text {. }
$$

Besides depth of poverty, $M_{2}$ is also sensitive on inequality within poor population. Like $M_{1}$, it cannot be calculated based on ordinal data.

In practice, indices from AF class of multidimensional poverty indices are constructed through several phases.

In the first phase, identification of poor, the thresholds for each indicator should be defined and identified poor units for each indicator. If needed, weights are assigned to each indicator and calculated weighted sum by chosen dimensions - indicators. It is required to determine overall poverty threshold that relates to number of deprivation by indicators, in order to identify multidimensionally poor.

Proportion of poor units - multidimensional headcount ratio $P_{1}$ is calculated at the second phase, based on deprivation matrix:

$$
D=\left[d_{i j}\right]_{n \times m}, \text { where } d_{i j}=\left\{\begin{array}{l}
1, x_{i j} \leq z_{j} \\
0, x_{i j}>z_{j}
\end{array} .\right.
$$

The average deprivation share $A_{s}$ is determined as the average of (weighted) deprivation of poor units. The adjusted headcount ratio $M_{0}$ is calculated based on $P_{1}$ and $A_{s}$. If data are not ordinal, $M_{1}, M_{2}, \ldots$ can be calculated.

The indices from AF class allow decomposition by geographic regions, ethnic groups or other population classifications and thus enable detection of deprivations that are poverty holders within the groups. For policy creators, AF method also enables discovering of similar characteristics of poverty within and across the groups, which is significant to adjust social assistance programs.

They are suitable for analysis of poverty dynamics through time series or panel data. Thanks to comparability over time, it is easier to spot the effects of social policies. For example, if the social policy was directed towards improving education, measuring effects through income based indices requires longer period of time. In contrast, if the number of enrolled students is included in multidimensional index, the effect will be able to observe for much less time.

\section{Multidimensional fuzzy poverty indices}

In set theory, for set $A \subseteq Y$, characteristic or identification function $\chi_{A}: Y \rightarrow\{0,1\}$ is defined by:

$$
\chi_{A}(y)=\left\{\begin{array}{l}
1, y \in A \\
0, y \notin A
\end{array}, y \in Y .\right.
$$

The term of fuzzy subsets is introduced by Zadeh (1965). Fuzzy subset A of nonempty set $Y$ is characterized by membership function:

$$
\mu_{A}: Y \rightarrow[0,1] \text {, }
$$

where $\mu_{A}(y)$ represents the membership level of element $y$ to fuzzy subset $A$, for each $y \in Y$. Subset $A$ is determined by set of ordered pairs:

$$
\left\{\left(y, \mu_{A}(y), y \in Y\right\}\right. \text {. }
$$


If $\mu_{A}(y)=1$ then element $y \in Y$ completely belongs to fuzzy subset $A$, and if $\mu_{A}(y)=$ 0 then element $y \in Y$ completely doesn't belong to fuzzy subset $A$. The values between 0 and 1 represent intermediate level of membership to fuzzy subset $A$.

Fuzzy set approach to multidimensional poverty measurement utilized fuzzy sets theory to define poverty membership function which assigns level of poverty to each population unit. Let $P$ be fuzzy subset of poor population unit. According to (7) $P$ can be defined by:

$$
P=\left\{\left(i, \mu_{P}(i)\right), i=\overline{1, n}\right\},
$$

where $n$ is population size, $i$ represents population unit, $i=\overline{1, n}$ and $\mu_{P}(i)$ represents poverty level of unit $i$ or membership level of unit $i$ to poverty fuzzy subset $P$ :

$$
\mu_{P}(i)\left\{\begin{array}{l}
=0, \text { if population } i \text { unit is absolutelynonpoor } \\
=1, \text { if population unit } i \text { is absolutely poor } \\
\in(0,1), \text { if population unit } i \text { is partially poor }
\end{array} .\right.
$$

Population is usually set of households or individuals $(i=\overline{1, n})$ and poverty fuzzy subset $P$ is subset of partially or completely poor households or individuals. Assume that poverty analysis is based on set of $m$ poverty indicators $y_{j}, j=\overline{1, m}$.

The construction of membership function $\mu_{P}$, given in (9), depends on poverty indicator type: a) binary (dichotomous), and b) categorical or continuous. Let's define indicator types:

a)Binary indicators $y_{j}$ - The possession of certain durable good (e.g. possession of phone line - yes/no) or certain housing characteristics (e.g. running water - yes/no) are typical example of binary poverty indicator. In that sense, the units that possess certain durable good or housing characteristic are considered as units with lower poverty or deprivation risk and vice versa. The value of 1 on given attribute is considered as the lowest risk and the value of 0 is considered as the highest risk. For each binary indicator $y_{j}$, poverty membership function $\mu_{P}$ of unit $i$ to poverty fuzzy subset $B_{j}$ is defined by:

$\mu_{B_{j}}(i)=\left\{\begin{array}{l}1, \text { if } y_{i j}=0\left(i \text { belongs to fuzzy subset } B_{j} \text {-doesn't possess good/characterstic } j\right) \\ 0, \text { if } y_{i j}=1\left(i \text { doesn't belong to fuzzy subset } B_{j} \text {-possesses good/characteristic } j\right)\end{array}\right.$

where $y_{i j}$ is value of binary poverty indicator $y_{j}$ of unit $i$ and $B_{j}$ is poverty fuzzy subset that corresponds to indicator $y_{j}$.

b)Categorical or continuous indicators $y_{j}$ - The most of poverty indicators are categorical ordinal or continuous variables. If certain indicator $y_{j}$ is categorical, then its values can be assigned with the numerical values (e.g. education level: 1 - no school, 2 - primary school, etc.). Income and consumption expenditure are typical examples of continuous poverty indicators. Suppose that categorical ordinal and continuous indicators are arranged in such a way that higher value is considered as higher poverty risk. Let $y_{j \min }$ be the lowest value of $y_{j}$ so each unit $i$ with $y_{j}<y_{\text {jmin }}$ is undoubtedly considered as poor and $y_{\text {jmax }}$ be the highest value of $y_{\text {jmin }}$ so each unit $i$ with $y_{j}>y_{\text {jmax }}$ is undoubtedly considered as nonpoor. The units $i$ that satisfy $y_{\text {jmin }}<y_{j}<y_{\text {jmax }}$ are considered as partly poor. Cerioli and Zani (1990) proposed definition of poverty membership function $\mu_{P}$ of unit $i$ to poverty fuzzy subset $C_{j}$ that corresponds to categorical ordinal or continuous indicator $y_{j}$ : 


$$
\mu_{C_{j}}(i)=\left\{\begin{array}{l}
1, \text { if } 0<y_{i j}<y_{\text {min }} \\
\frac{y_{\text {max }}-y_{i j}}{y_{\text {max }}-y_{\text {min }}}, \text { if } y_{\text {min }} \leq y_{i j} \leq y_{\text {max }} . \\
0, \text { if } y_{i j}>y_{\text {max }}
\end{array}\right.
$$

Aiming to construct composite poverty index, defined values of poverty membership function for different types of indicators need to be aggregated. Costa and De Angelis $(2002,2008)$ proposed unidimensional fuzzy poverty index, assigned to indicator $y_{j}$, as weighted average of membership function values for indicator $y_{j}$ :

$$
C_{P_{j}}=\frac{\sum_{i=1}^{n} n_{i} \mu_{P_{j}}(i)}{\sum_{i=1}^{n} n_{i}}=\frac{1}{n} \sum_{i=1}^{n} n_{i} \mu_{P_{j}}(i),
$$

where $n_{i}$ represents weight assigned to unit $i$ and $\sum_{i=1}^{n} n_{i}=n$.

Further, Costa and De Angelis proposed technique for construction multidimensional fuzzy poverty index by aggregating unidimensional indices given by (12). Multidimensional fuzzy poverty index is defined as the weighted average of unidimensional poverty indices $C_{P_{j}}, j=\overline{1, m}$, as follows:

$$
C_{P}=\frac{\sum_{j=1}^{m} w_{j} C_{P_{j}}}{\sum_{j=1}^{m} w_{j}}
$$

where $w_{j}, j=\overline{1, m}$ are indicator weights given by:

$$
w_{j}=\log \frac{n}{\sum_{i=1}^{n} n_{i} \mu_{B_{j}}(i)} \geq 0, j=\overline{1, m} .
$$

Multidimensional fuzzy poverty index $C_{P}$, defined by (14) is monotone increasing function of poverty/deprivation level of observational unit. Deterioration of living condition, ceteris paribus, will result in increase of $C_{p}$. The presented method of multidimensional fuzzy poverty index definition is totally fuzzy approach. Some authors suggest modification of this approach in order to reduce arbitrariness in choosing of threshold values for categorical and continuous poverty indicators. The new approach, totally fuzzy and relative approach, is proposed by Cheli and Lemmi (1995).

Let $P_{j}$ be subset of observational units, households or individuals, which are classified as poor or deprived considering $j$-th indicator, $j=1,2, \ldots, m$. Indicators $y_{j}, j=$ $\overline{1, m}$ are binary, categorical or continuous variables. Let $F_{j}$ be distribution function of $j$ th indicator. The membership function can be defined in two ways, depending of relationship between poverty level and values of indicator. In the first case, if poverty level increases when values of indicator $y_{j}$ increases, the membership function is defined by:

$$
\mu_{P_{j}}(i)=F\left(y_{i j}\right) \text {. }
$$

If poverty level decreases when values of indicator $y_{j}$ increases, the membership function is defined by:

$$
\mu_{P_{j}}(i)=1-F\left(y_{i j}\right) .
$$


Chelli and Lemmi (1995) emphasize that this way in defining membership function is less arbitrary comparing to totally fuzzy approach, considering that doesn't require defining of threshold values for categorical and continuous indicators. Also, this approach allows definition of relative poverty, which is widely used concept in the most of developed countries.

After determining the poverty level of each observational unit that corresponds with $j$-th indicator $(j=1,2, . ., m)$, it is needed to aggregate different indicators of poverty/deprivation. The overall membership function of multidimensional poverty for $i$-th observational unit is defined by:

$$
\mu_{P}(i)=\sum_{j=1}^{m} w_{j} \mu_{P_{j}}(i) .
$$

Cheli and Lemmi (1995) suggest the following choice of indicator weights:

$$
w_{j}=\frac{\ln \left(\frac{1}{\mu f_{P_{j}}}\right)}{\sum_{j=1}^{m} \ln \left(\frac{1}{\mu f_{P_{j}}}\right)}=\frac{\ln \left(\mu f_{P_{j}}\right)}{\sum_{j=1}^{m} \ln \left(\mu f_{P_{j}}\right)},
$$

where $\mu f_{P_{j}}=\frac{1}{n} \sum_{i=1}^{n} \mu_{P_{j}}(i)$ represents fuzzy proportion of poor population units in relation to $j$-th poverty/deprivation indicator $y_{j}$. The weights defined by (18) will have higher value for indicators with the lower frequency. For example, if the "lack of running water" is less frequent than "lack of internet access", then higher weight will be assigned to indicator "lack of running water" than to indicator "lack of internet access".

The overall fuzzy poverty index $C_{p}$, based on totally fuzzy and relative approach, is defined as the average value of individual values of overall multidimensional poverty functions defined by (17), across the population, as follows:

$$
C_{P}=\frac{1}{n} \sum_{i=1}^{n} \mu_{P}(i) \text {. }
$$

\section{Data and results}

As a source of data, this study utilizes datasets from three waves of Household Budget Survey in Bosnia and Herzegovina, conducted in 2004, 2007 and 2011. The fourth wave of HBS was conducted in 2015, but the datasets are not finally prepared and available for the researchers. Datasets contain data collected on the samples of more than 7400 households i.e. more than 22000 individuals (household members). Basic monetary poverty measure in HBS B\&H is equivalised monthly household consumption expenditure.

\section{Unidimensional poverty indices}

As a basis for comparisons, authors calculated unidimensional Foster-GreerThorbecke poverty indices, based on equivalised monthly household consumption expenditure, for Federation of Bosnia and Herzegovina (FB\&H), Republika Srpska (RS), Brčko District (BD) and entire Bosnia and Herzegovina B\&H). The results on datasets from three waves of HBS are presented in Table 1 and Figure 1. 
Table 1 Unidimensional Foster-Greer-Thorbecke indices for B\&H, FB\&H, RS and BD

\begin{tabular}{|l|c|c|c|c|c|c|c|c|c|}
\cline { 2 - 10 } \multicolumn{1}{c|}{} & \multicolumn{3}{c|}{\begin{tabular}{c} 
Headcount ratio (Po) \\
\multicolumn{1}{c|}{}
\end{tabular}} & \multicolumn{3}{c|}{ Poverty gap index $\left(\mathrm{P}_{1}\right)$} & \multicolumn{3}{c|}{ Poverty severity index } \\
\cline { 2 - 11 } & 2004 & 2007 & 2011 & 2004 & 2007 & 2011 & 2004 & 2007 & 2011 \\
\hline B\&H & 18.08 & 18.37 & 17.15 & 4.28 & 4.81 & 4.32 & 0.016 & 0.019 & 0.017 \\
FB\&H & 18.30 & 16.31 & 15.96 & 4.62 & 4.12 & 4.25 & 0.017 & 0.016 & 0.011 \\
RS & 18.28 & 21.67 & 19.63 & 3.91 & 5.96 & 4.57 & 0.013 & 0.024 & 0.017 \\
BD & 7.81 & 23.56 & 12.18 & 1.19 & 6.16 & 2.53 & 0.003 & 0.022 & 0.008 \\
\hline
\end{tabular}

Source: Authors' calculation.

According to values of headcount ratio, the percentage of poor in the entire $\mathrm{B} \& \mathrm{H}$ had not suffer major changes during the observed period - approximately $18 \%$ in 2004 and 2007 with the tendency of decline in 2011 - approximately 17\%. Poverty in $\mathrm{FB} \& \mathrm{H}$ is in permanent decline. Deterioration of poverty rate in RS and BD is recorded in 2007. In 2011, poverty decreased in these areas, but not under the level in 2004.

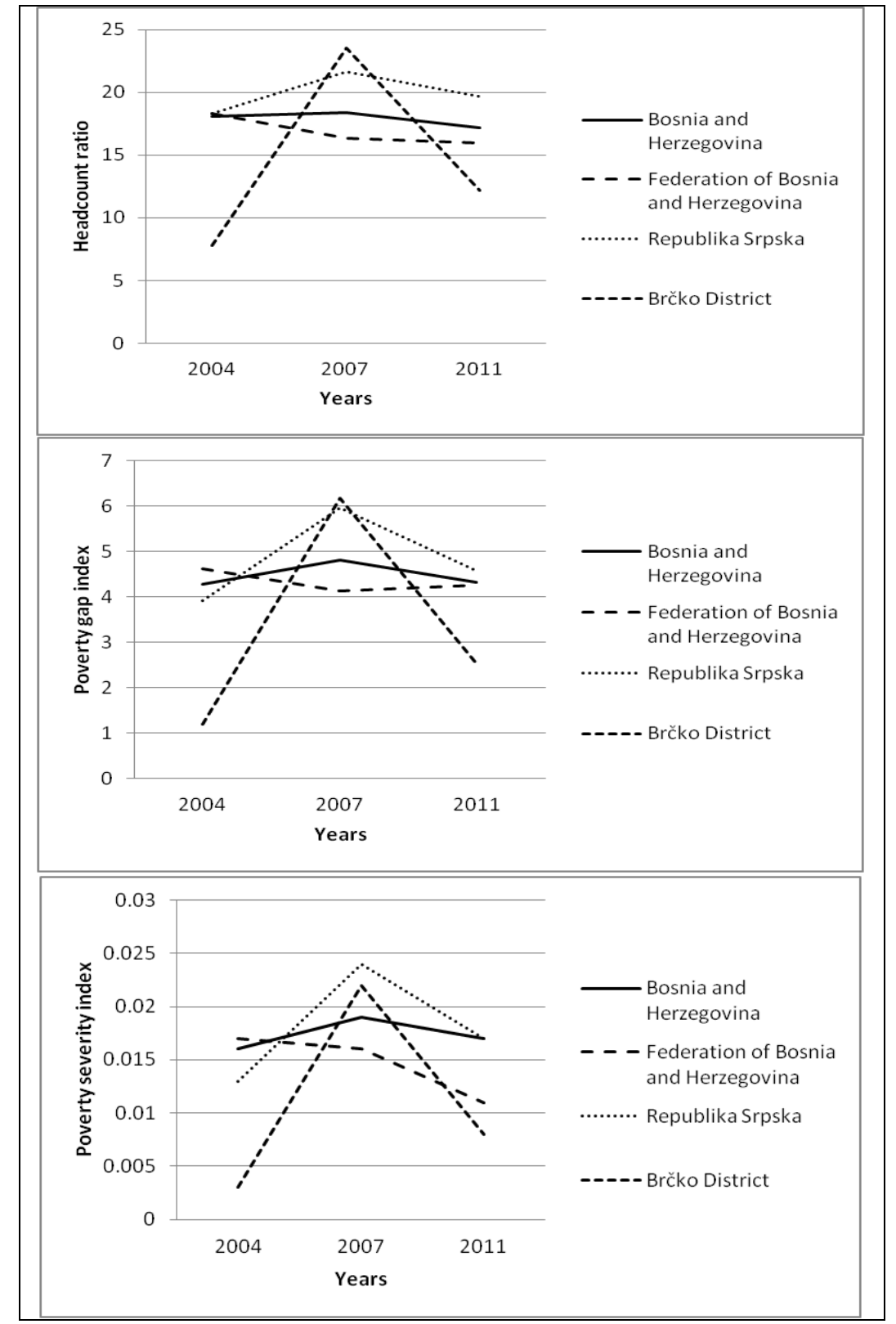

Figure 1 Graphical presentation of unidimensional FGT indices Source: Authors' creation. 
Poverty depth, measured by poverty gap index, recorded close values in the observed period in B\&H and FB\&H, while poverty depth and poverty severity, measured by poverty gap and poverty severity indices were the highest in 2007 and the lowest in 2004 in RS and BD. Poverty severity was declining during the whole period in FB\&H but deterioration in RS and BS resulted by increasing of poverty severity in B\&H in 2007. Only in FB\&H poverty severity is lower in 2011 than 2004.

\section{Alkire - Foster adjusted headcount ratio}

For the purposes of this study, multidimensional poverty indices based on AF method were calculated based on datasets from HBS 2004, 2007 and 2011. Aiming to cover as more as possible relevant characteristics and living standard aspects, the following indicators were considered:

Indicators of housing quality: indoor toilet and bathroom, running water, electricity and public sewer and

Possession of durable goods: electric/wood/gas stove, fridge/freezer, washing machine, cleaning equipment (vacuum cleaner, etc.), car, phone or mobile phone, TV, DVD or VCR player, HI-FI systems (CD, MP3, etc.), computer and internet access.

In order to cover monetary aspect of poverty, binary variable poor (yes/no), based on equivalised monthly household consumption expenditure and relative poverty threshold is included.

The percentages of households in B\&H, FB\&H, RS and BD for 2004, 2007 and 2011 , that are deprived by individual items, are presented in the Table 2.

Table 2 Percentages of deprivation

\begin{tabular}{|c|c|c|c|c|c|c|c|c|c|c|c|c|}
\hline \multirow{2}{*}{$\begin{array}{l}\text { Item/character. } \\
\text { (\% deprived) }\end{array}$} & \multicolumn{3}{|c|}{$\mathrm{B} \& \mathrm{H}$} & \multicolumn{3}{|c|}{ FB\&H } & \multicolumn{3}{|c|}{ RS } & \multicolumn{3}{|c|}{$\mathrm{BD}$} \\
\hline & 2004 & 2007 & 2011 & 2004 & 2007 & 2011 & 2004 & 2007 & 2011 & 2004 & 2007 & 2011 \\
\hline Indoor toilet & 11.0 & 6.9 & 4.8 & 7.0 & 4.1 & 2.4 & 17.7 & 12.0 & 8.9 & 7.4 & 5.0 & 5.2 \\
\hline Running water & 10.5 & 5.9 & 14.1 & 7.7 & 3.1 & 4.3 & 15.4 & 10.4 & 30.7 & 6.2 & 11.1 & 31.7 \\
\hline Electricity & 0.5 & 0.1 & 0.0 & 0.4 & 0.0 & 0.0 & 0.7 & 0.4 & 0.1 & 0.0 & 0.0 & 0.2 \\
\hline Public sewer & 55.4 & 52.3 & 46.8 & 48.4 & 44.7 & 40.1 & 68.0 & 66.2 & 60.0 & 34.7 & 42.7 & 31.9 \\
\hline Stove & 0.2 & 0.1 & 0.2 & 0.2 & 0.1 & 0.1 & 0.1 & 0.1 & 0.2 & 0.0 & 1.1 & 0.2 \\
\hline Fridge/freezer & 4.0 & 2.4 & 1.3 & 3.7 & 1.7 & 1.0 & 4.8 & 3.7 & 1.9 & 0.8 & 0.6 & 1.7 \\
\hline Washing machine & 20.9 & 13.9 & 8.1 & 17.4 & 10.5 & 5.8 & 26.8 & 19.9 & 12.3 & 15.2 & 13.3 & 6.0 \\
\hline Cleaning equipment & 16.7 & 11.2 & 5.7 & 13.9 & 8.1 & 3.9 & 21.9 & 17.0 & 9.0 & 12.0 & 7.0 & 5.5 \\
\hline Car & 52.5 & 48.1 & 46.4 & 51.3 & 46.7 & 44.5 & 54.9 & 50.4 & 50.0 & 43.1 & 47.8 & 42.1 \\
\hline Phone, mobile phone & 19.9 & 7.9 & 4.7 & 14.8 & 5.3 & 3.3 & 27.6 & 12.2 & 7.4 & 29.9 & 10.2 & 3.0 \\
\hline TV & 5.0 & 3.2 & 1.6 & 3.8 & 2.2 & 1.0 & 7.3 & 5.2 & 2.8 & 1.1 & 1.1 & 0.9 \\
\hline DVD, VCR player & 54.0 & 42.9 & 37.1 & 48.8 & 34.8 & 30.0 & 63.0 & 56.9 & 50.7 & 45.7 & 46.4 & 27.7 \\
\hline HI-FI systems & 56.8 & 37.2 & 39.9 & 45.4 & 27.8 & 29.9 & 75.1 & 51.8 & 57.4 & 62.8 & 68.3 & 47.9 \\
\hline Computer & 87.3 & 74.8 & 60.4 & 85.5 & 71.8 & 57.4 & 90.3 & 79.6 & 65.6 & 86.0 & 82.3 & 62.8 \\
\hline Internet access & 93.4 & 81.6 & 70.2 & 95.2 & 87.7 & 67.8 & 95.2 & 91.3 & 74.5 & 93.7 & 94.6 & 70.3 \\
\hline Percentage of poor & 18.1 & 18.4 & 17.2 & 18.3 & 16.3 & 16.0 & 18.3 & 21.7 & 19.6 & 7.8 & 23.6 & 12.2 \\
\hline
\end{tabular}

Source: Authors' calculation.

Generally, results show that indicators of housing quality, possession of durable goods and percentage of poor are significantly worse in RS compared to FB\&H and $\mathrm{BD}$. The most of indicators have trend of improvement in the observed period. The exception is the percentage of households with running water inside the housing unit. That percentage, for RS and BD is above $30 \%$ in 2011 although that percentage was significantly lower in 2004 and 2007, for both areas. In FB\&H, that percentage permanently decreases in the observed period.

Aiming to construct multidimensional indices based on AF method, it is needed to determine a set of poverty indicators. Robustness analysis and setting of adequate 
poverty threshold were performed on the basis on data from 2011. In order to determine the overall poverty line, we considered that unidimensional poverty line for B\&H was $17.15 \%$, and for FB\&H, RS and BD it was between $12.18 \%$ and $19.63 \%$, in 2011 . Different combinations of input indicator sets were tested: all 16 indicators, 14 indicators (without possession of computer and internet access) and 12 indicators (without possession of computer, internet access, Hi-Fi systems and DVD/VCR players). For each combination of indicators, several multidimensional poverty thresholds were tested. The robustness analysis was extended with calculation of percentages of multidimensional poor based on data from 2004 and 2007, for entire $B \& H$ and separately for FB\&H, RS and BD.

Based on the analysis of the distribution of number of deprivations for sets of 16, 14 and 12 indicators and considering general poverty rate in 2011, there were chosen following overall poverty thresholds (Table 3).

Table 3 Overall poverty thresholds and the percentage of multidimensionally poor for B\&H (2011)

\begin{tabular}{|c|c|c|}
\hline $\begin{array}{c}\text { No. of } \\
\text { indicators }\end{array}$ & $\begin{array}{c}\text { Overall poverty threshold (Criteria } \\
\text { for multidimensional poverty) }\end{array}$ & $\begin{array}{c}\text { \% of poor (multidimensional } \\
\text { headcount ratio) }\end{array}$ \\
\hline 16 & At least 6 deprivations & $20.5 \%$ \\
14 & At least 4 deprivations & $21.8 \%$ \\
12 & At least 3 deprivations & $17.6 \%$ \\
\hline
\end{tabular}

Source: Authors' calculation.

In the cases of three chosen sets of poverty indicators, according to determined poverty thresholds, there were calculated multidimensional headcount ratios (the percentages of multidimensionally poor) for $B \& H, F B \& H, R S$ and $B D$. The results are presented in Table 4.

Table 4 The percentages of multidimensionally poor for three sets of poverty indicators for $B \& H, F B \& H, R S$ and $B D(2011)$

\begin{tabular}{|c|c|c|c|c|}
\cline { 3 - 5 } Area & $\begin{array}{c}\text { \% of } \\
\text { unidimensionally } \\
\text { poor (consumption) }\end{array}$ & $\begin{array}{c}\text { \% of multidimensionally poor } \\
\text { indicators }\end{array}$ & $\begin{array}{c}14 \\
\text { indicators }\end{array}$ & $\begin{array}{c}12 \\
\text { indicators }\end{array}$ \\
\hline B\&H & $17.2 \%$ & $20.5 \%$ & $21.8 \%$ & $17.6 \%$ \\
FB\&H & $16.0 \%$ & $13.7 \%$ & $14.5 \%$ & $11.6 \%$ \\
RS & $19.6 \%$ & $33.1 \%$ & $35.4 \%$ & $28.5 \%$ \\
BD & $12.2 \%$ & $15.6 \%$ & $16.2 \%$ & $15.5 \%$ \\
\hline
\end{tabular}

Source: Authors' calculation.

The closest value to the unidimensional poverty rate in B\&H was obtained for the set of 12 indicators. Also, in a case of RS, the difference between multidimensional and unidimensional poverty rate is the lowest for that combination of indicators. That was the reason for choosing the set of 12 poverty indicators for construction of multidimensional AF poverty index. Adjusted headcount ratio (Mo), by AF method, was calculated for B\&H, FB\&H, RS and BD (2004, 2007 and 2011).

The values of multidimensional headcount ratios $P_{0}$, average deprivation share (poverty intensity) As and AF adjusted headcount ratios Mo are presented in Table 5. 
Table 5 Multidimensional $P_{0}, A_{s}$ and $M_{0}$ for $B \& H, F B \& H, R S$ and $B D$

\begin{tabular}{|l|c|c|c|c|c|c|c|c|c|}
\hline \multirow{2}{*}{ Area } & \multicolumn{3}{|c|}{ Year 2004 } & \multicolumn{3}{c|}{ Year 2007 } & \multicolumn{3}{c|}{ Year 2011 } \\
\cline { 2 - 10 } & $P_{0}$ & $A_{s}$ & $M_{0}$ & $P_{0}$ & $A_{s}$ & $M_{0}$ & $P_{0}$ & $A_{s}$ & $M_{0}$ \\
\hline B\&H & 0.267 & 0.426 & 0.114 & 0.206 & 0.421 & 0.087 & 0.176 & 0.376 & 0.066 \\
FB\&H & 0.212 & 0.403 & 0.085 & 0.159 & 0.387 & 0.061 & 0.116 & 0.351 & 0.041 \\
RS & 0.360 & 0.449 & 0.162 & 0.289 & 0.455 & 0.131 & 0.285 & 0.395 & 0.112 \\
BD & 0.205 & 0.367 & 0.075 & 0.209 & 0.382 & 0.080 & 0.155 & 0.378 & 0.059 \\
\hline
\end{tabular}

Source: Authors' calculation.

Graphical presentation of calculated values of multidimensional headcount ratio, average deprivation share and adjusted headcount ratio is given on Figure 2.

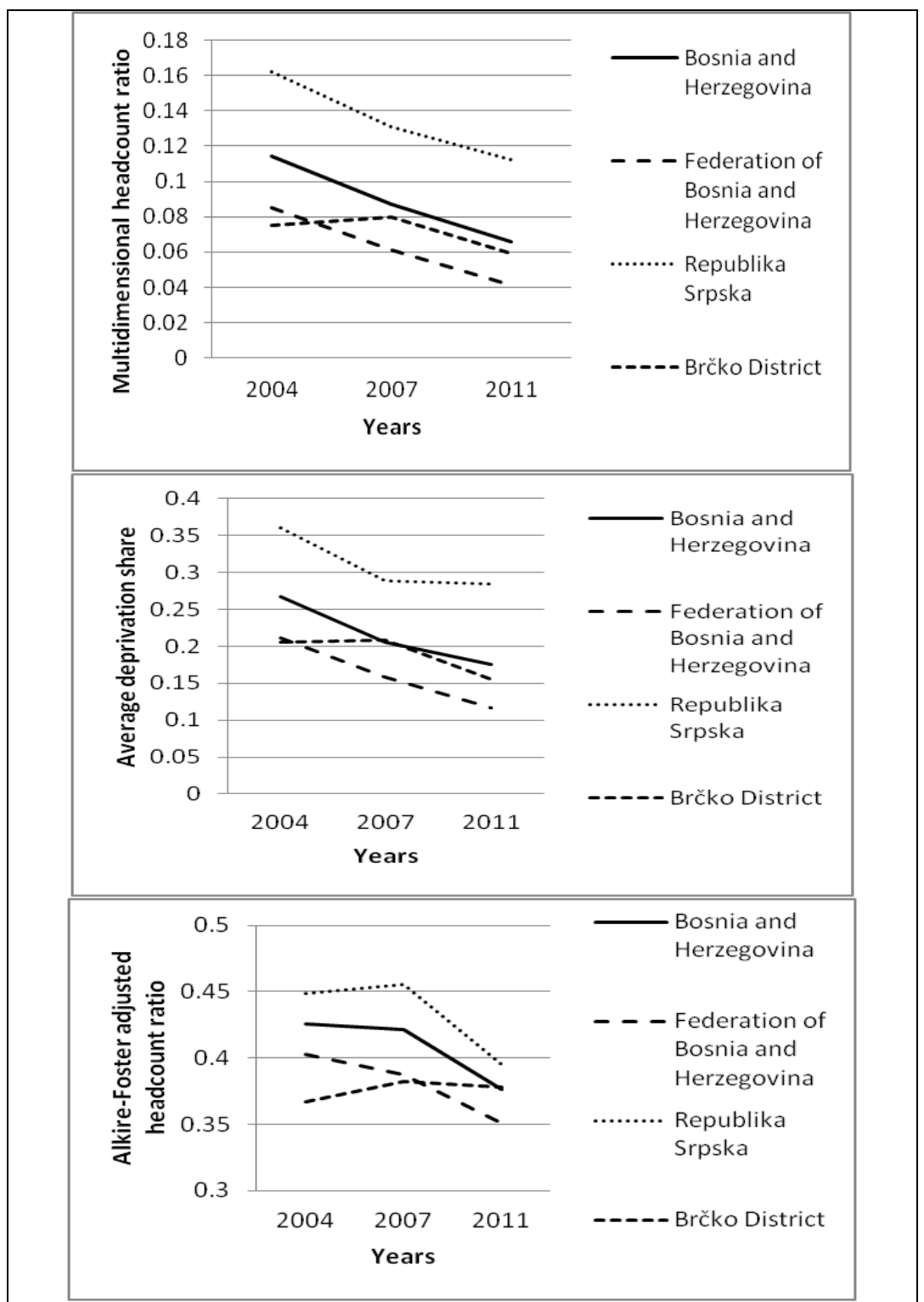

Figure 2 Graphical presentation of multidimensional $P_{0}, A_{s}$ i $M_{0}$ for $B \& H, F B \& H, R S$ and Source: Authors' creation. $\operatorname{BD}(2004,2007$ and 2011$)$

Unidimensional poverty indices (Table 1) show deterioration of percentage, depth and severity of poverty for RS and BD in 2007 which resulted in deterioration in B\&H. In contrast, adjusted headcount ratio (Mo) shows permanent decreasing of 
multidimensional poverty in period 2004-2011. The percentage of multidimensionally poor, measured by multidimensional headcount ratio $\left(P_{0}\right)$, also decreased in all areas in the observed period. Intensity of poverty, measured by average deprivation share $\left(A_{s}\right)$ decreased in $B \& H$ and FB\&H while intensity of poverty was the highest in 2007, for RS and BD. As well as in the case of unidimensional indices, multidimensional poverty and poverty intensity were worse in RS and BD compared to FB\&H.Generally, unidimensional and multidimensional poverty didn't show the similar dynamics in period $2004-2011$.

\section{Fuzzy multidimensional index}

Due to complexity of calculation, for the purpose of this study, fuzzy multidimensional indices for B\&H, FB\&H, RS and BD were calculated based on HBS 2011 dataset. In order to reduce arbitrariness, totally fuzzy and relative approach was used. Selected ten indicators were classified in following groups:

Housing quality: age of housing unit, housing area $\left(\mathrm{m}^{2}\right)$ per household member, number of household members by room, housing equipment (aggregated: running water, heating, electricity and public sewer), durable goods (aggregated possession of: stove, fridge, washing machine, cleaning equipment, car, phone or mobile phone, TV, DVD/VCR player and computer);

Financial status: equivalised monthly household consumption expenditure, ratio of estimated the lowest income needed and realized monthly consumption expenditure;

Household structure - education, employment, vulnerability: household head education, number of employed per household member and number of dependent (children and older) per household member.

In order to determine membership function for each of chosen poverty indicator, it is necessary to classify poverty indicators into two classes: (I) class of indicators with characteristic that poverty increases if value of poverty indicator increases and (II) class with characteristic that poverty decreases if value of poverty indicator increases. According to this definition, class (I) consisted of: age of housing unit, number of household members per room, housing equipment, durable goods, ratio of estimated the lowest income needed and realized monthly consumption expenditure and number of dependent per household member. The indicators housing equipment and durable goods are defined in such way that higher value of indicator represents poorer household. Class (II) consisted of: housing area per household member, equivalised monthly household consumption expenditure, household head education and number of employed per household member.

Poverty membership function $\mu_{P_{j}}$ for indicators that belong to class (I) were calculated by using definition (15), since for indicators that belong to class (II), definition (16) was used.

After membership functions were determined for all included indicators, there were calculated $\mu f_{P_{j}}$ - fuzzy proportions of poor households for each indicator, as the average value of poverty membership functions across households. By using formulas (17), (18) and (19), fuzzy multidimensional poverty indicators were constructed.

Fuzzy proportions of poor households and calculated weights for each of 10 poverty indicator, such as overall fuzzy multidimensional indices for B\&H, FB\&H, RS and $\mathrm{BD}$ are presented in Table 6. 
Table 6 Fuzzy proportions of poor and fuzzy indices for B\&H, FB\&H, RS and BD in 2011

\begin{tabular}{|c|c|c|c|c|c|c|c|c|}
\hline & \multicolumn{2}{|c|}{$\mathrm{B} \& \mathrm{H}$} & \multicolumn{2}{|c|}{ FB\&H } & \multicolumn{2}{|c|}{ RS } & \multicolumn{2}{|c|}{$\mathrm{BD}$} \\
\hline Indicator & $\begin{array}{c}\text { Fuzzy } \\
\text { proportion } \\
\text { of poor }\end{array}$ & Weight & $\begin{array}{l}\text { Fuzzy } \\
\text { proportion } \\
\text { of poor }\end{array}$ & Weight & $\begin{array}{l}\text { Fuzzy } \\
\text { proportion } \\
\text { of poor }\end{array}$ & Weight & $\begin{array}{l}\text { Fuzzy } \\
\text { proportion } \\
\text { of poor }\end{array}$ & Weight \\
\hline Age of h. unit & 0.3485 & 0.0539 & 0.3454 & 0.0598 & 0.3476 & 0.0641 & 0.3437 & 0.0955 \\
\hline Area/member & 0.6688 & 0.0205 & 0.6788 & 0.0218 & 0.6727 & 0.0241 & 0.6774 & 0.0348 \\
\hline Members/room & 0.0411 & 0.1625 & 0.2077 & 0.0885 & 0.0625 & 0.1683 & 0.3713 & 0.0886 \\
\hline H. equipment & 0.0643 & 0.1397 & 0.0658 & 0.1532 & 0.1461 & 0.1167 & 0.0483 & 0.2711 \\
\hline Durable goods & 0.2563 & 0.0693 & 0.2194 & 0.0854 & 0.2744 & 0.2744 & 0.2575 & 0.1213 \\
\hline Consumption & 0.6551 & 0.0215 & 0.6435 & 0.0248 & 0.6512 & 0.0260 & 0.6438 & 0.0394 \\
\hline $\begin{array}{l}\text { Lo.income } \\
\text { /consumption }\end{array}$ & 0.0003 & 0.4186 & 0.0004 & 0.4389 & 0.0017 & 0.3883 & 0.1780 & 0.1544 \\
\hline $\begin{array}{l}\text { H. head } \\
\text { education }\end{array}$ & 0.6117 & 0.0250 & 0.5968 & 0.0291 & 0.6122 & 0.02988 & 0.6906 & 0.0443 \\
\hline $\begin{array}{l}\text { No. employed } \\
\text { /member }\end{array}$ & 0.7827 & 0.0125 & 0.7787 & 0.0141 & 0.7826 & 0.0149 & 0.7976 & 0.0202 \\
\hline $\begin{array}{l}\text { No. dependent } \\
\text { /member }\end{array}$ & 0.2220 & 0.0766 & 0.2232 & 0.0844 & 0.2295 & 0.0893 & 0.2331 & 0.1303 \\
\hline Fuzzy index & \multicolumn{2}{|c|}{0.2132} & \multicolumn{2}{|c|}{0.2012} & \multicolumn{2}{|c|}{0.2275} & \multicolumn{2}{|c|}{0.3690} \\
\hline
\end{tabular}

Source: Authors' calculation.

In FB\&H, RS and entire B\&H, the highest fuzzy proportion of poor was recorded in case of indicator number of employed per household member, followed by fuzzy proportion of poor for indicators housing area per household member and equivalised monthly household consumption expenditure. In case of BD, fuzzy proportion of poor for indicator number of employed per household member is also the highest one, but on the second place is fuzzy proportion of poor for indicator education of household head, which is followed by housing area per household member and equivalised monthly household consumption expenditure.

Overall fuzzy poverty index, in 2011 is significantly higher in BD compared to values of this index in FB\&H, RS and entire B\&H. This result is in contrast to conclusions obtained by unidimensional poverty indices that show lower poverty in BD compared to other areas, in 2011. Although earlier calculated unidimensional indices consider depth and intensity of poverty, it should be noted that these indices were calculated according to predefined poverty thresholds.

Based on datasets form HBS 2011, this study spots the difference between measurement of poverty based on predefined poverty thresholds in construction of unidimensional poverty indices, and the measurement based on level of poverty affiliation in construction of multidimensional fuzzy poverty indices.

\section{Conclusions}

In comparison of results of undidimensional poverty measurement and multidimensional poverty measurement in Bosnia and Herzegovina, we concluded that adjusted headcount ratio, constructed by Alkire - Foster method, such as corresponding poverty intensity measure - the average deprivation share, don't follow dynamics of incidence and intensity of poverty indicated by unidimensional poverty measures based on households consumption expenditure.

In contrast to calculated unidimensional indices, AF adjusted headcount ratio indicates permanent decreasing of poverty in a period $2004-2011$.

If poverty in Bosnia and Herzegovina is measured without predefined poverty lines and classification of households in poor and nonpoor, fuzzy approach for poverty measurement indicates significant differences between results based on unidimensional indices and multidimensional fuzzy indices. 
Conclusions based on fuzzy proportions of poor households emphasize proxy variable for participation of household in labor force as the variable with the highest proportion of poor households. Accordingly, poverty cannot be measured, reduced and evaluated without policies that will include progressive employment strategies and reducing unemployment rate.

Although multidimensionality of poverty is undisputed and there is no need to prove and confirm, the most of surveys that are used as a base for reducing poverty are based almost exclusively on monetary poverty indicators.

Results obtained in this study, based on data from the most comprehensive survey in Bosnia and Herzegovina, undoubtedly confirm that measurement and analysis of poverty shouldn't be based exclusively on monetary indicators and predefined poverty thresholds. Also, by including more nonmonetary poverty indicators and by reducing of arbitrariness in defining of poverty thresholds, there were obtained different structure and dynamics of poverty of Bosnia and Herzegovina compared to results of unidimensional analysis.

According to this conclusion, creation of social policy, strategies for poverty reduction and eradication and especially evaluation and measurement of their efficiency, shouldn't be based exclusively on monetary poverty indicators and unidimensional poverty indices. In order to create more efficient policies and strategies to reduce of poverty, official analysis and researches should be extended and enriched with additional indicators and techniques for multidimensional poverty measurement and identification.

\section{References}

1. Alkire, S., Foster, J. (2007). Counting and Multidimensional Poverty Measurement. Oxford Poverty and Human Development Initiative. Working Paper No. 7. Available at http://www.ophi.org.uk/wp-content/uploads/OPHI-wp32.pdf [03 November 2016].

2. Alkire, S., Foster, J. (2011). Counting and Multidimensional Poverty Measurement. Journal of Public Economics, Vol. 95, No. 7-8, pp. 476-487.

3. Alkire, S., Santos, M. E. (2011). Acute Multidimensional Poverty: A New Index for Developing Countries. Oxford Poverty and Human Development Intiative Working Paper No. 38. Available at http://www.ophi.org.uk/wp-content/uploads/OPHIwp38_with_note.pdf [03 November 2016].

4. Alkire, S., Santos, M. E. (2013). Measuring Acute Poverty Using the Multidimensional Poverty Index: Robust Comparisons and Future Prospects. Oxford Poverty and Human Development Intiative Working Paper No. 59. Available at http://www.ophi.org.uk/wpcontent/uploads/ophi-wp-59.pdf [03 November 2016].

5. Ambrosio, D., Deutsch, J., Silber, J. (2011). Multidimensional Approaches to Poverty Measurement: An Empirical Analysis of Poverty in Belgium, France, Germany, Italy and Spain, Based on European Panel. Applied Economics, Vol. 43, No. 8, pp. 951-972.

6. Betti, G., Cheli, B., Lemmi, A., Verma, V. (2006). On the construction of fuzzy measures for the analysis of poverty and social exclusion. Statistica \& Applicazioni, Vol. 4, No. 1, pp. 7797.

7. Cerioli, A., Zani, S. (1990). A Fuzzy Approach to the Measurement of Poverty. In Income and Wealth Distribution, Inequality and Poverty, Dagum, C., Zenga, M. (Eds.), Springer Verlag, Berlin, pp. 272-284.

8. Cheli, B., Lemmi, A. (1995). A Totally Fuzzy and Relative Approach to the Multidimensional Analysis of Poverty. Economic Notes, Vol. 24, No. 1, pp. 115-134.

9. Costa, M., De Angelis, L. (2008). The multidimensional measurement of poverty: a fuzzy set approach. Statistica, Vol. 68, No. 3-4, pp. 303-319.

10. Deutsch, J., Silber, J. (2006). The "Fuzzy Set" Approach to Multidimensional Poverty Analysis: Using the Shapley Decomposition to Analyze the Determinants of Poverty in 
Israel. In Fuzzy Set Approach to Multidimensional Poverty Measurement, Lemmi, A., Betti, G. (Eds.), Springer, New York, pp. 155-174.

11. Kakwani, N., Silber, J. (2008). Quantitative Approaches to Multidimensional Poverty Measurement. Palgrave Macmillan UK, London.

12. Lemmi, A., Betti, G. (2006). Fuzzy Set Approach to Multidimensional Poverty Measurement. Springer US, New York.

13. Zadeh, L. A. (1965). Fuzzy Sets. Information and Control, Vol. 8, No. 3, pp. 338-353.

\section{About the authors}

Adela Delalić is the assistant professor at the Department for Quantitative Economics, School of Economics and Business, University of Sarajevo, Bosnia and Herzegovina. Her fields of interests are Poverty and Inequality Analysis, Statistics, Applied Mathematics etc. She is the author of 2 university textbook, numerous of papers published in domestic and international journals and conferences, participant in several domestic and international projects and the member of several scientific and editorial teams. Author can be contacted at adela.delalic@efsa.unsa.ba.

Rabija Somun - Kapetanović is the full professor at the Department for Quantitative Economics, School of Economics and Business, University of Sarajevo, Bosnia and Herzegovina, and invited professor at the Faculty of Economics and Management, University of Strasbourg, France. She is the head of the chair of Department for Quantitative Economics at the School of Economics and Business, Sarajevo and the President of the Council for Statistics of Bosnia and Herzegovina. Her fields of interest are Statistics, Econometrics, Research methodology, etc. She is the author of 9 university textbooks and publications, numerous of papers and articles published in domestic and international journals and conferences, the leader or participant in numerous domestic and international projects and the member of several international journal's and conference's editorial advisory boards. She has large number of mentorships on PhD, master and graduation theses. Author can be contacted at rabija.somun@efsa.unsa.ba.

Emina Resić is the associate professor at the Department for Quantitative Economics, School of Economics and Business, University of Sarajevo, Bosnia and Herzegovina. Her fields of interest are Statistics, Econometrics, Qualitative research methodology etc. She is author and co-author of several textbooks and more than 50 articles in peer-reviewed journals and conferences proceedings. She has large number of mentorships on doctoral dissertations, master's works and graduation theses. She is reviewer for some international journals and publications and member of international conferences scientific programme committees. She can be contacted at emina.resic@efsa.unsa.ba. 